\title{
What makes a problem an ethical problem? An empirical perspective on the nature of ethical problems in general practice
}

Annette Joy Braunack-Mayer University of Adelaide, Australia

\begin{abstract}
Whilst there has been considerable debate about the fit between moral theory and moral reasoning in everyday life, the way in which moral problems are defined has rarely been questioned. This paper presents a qualitative analysis of interviews conducted with 15 general practitioners (GPs) in South Australia to argue that the way in which the bioethics literature defines an ethical dilemma captures only some of the range of lay views about the nature of ethical problems. The bioethics literature has defined ethical dilemmas in terms of conflict and choice between values, beliefs and options for action. While some of the views of some of the GPs in this study about the nature of their ethical dilemmas certainly accorded with this definition, other explanations of the ethical nature of their problems revolved around the publicity associated with the issues they were discussing, concern about their relationships with patients, and anxiety about threats to their integrity and reputation. The variety of views about what makes a problem a moral problem indicates that the moral domain is perhaps wider and richer than mainstream bioethics would generally allow.

(Fournal of Medical Ethics 2001;27:98-103)
\end{abstract}

Keywords: Empirical ethics; general practice; qualitative research

\section{Introduction}

There has been a spirited debate in recent years about the relationship between real life moral decision making and the forms, styles and content of reasoning used in bioethics. On the one hand, moral theorists and, in particular, bioethicists, present the view that their theories of moral reasoning provide a more rational and ordered account of the moral theorising we all do on a daily basis. ${ }^{1-4}$ On the other hand, critics of mainstream bioethics, particularly from the social sciences, argue that the forms, styles and language of bioethics bear little relationship to the ways in which ordinary people describe and explain their moral problems. ${ }^{56}$

This paper offers an empirical contribution to this debate, drawing on data and analysis of semi-structured interviews conducted with general practitioners (GPs) in South Australia. It uses the GPs' talk about the problems they described as "moral" or "ethical" to explore the question: "do lay people interpret ethical problems as mainstream bioethics does?" I argue that the way in which the bioethics literature has defined ethical dilemmas captures only some of the range of these GPs' views about the nature of ethical problems. A broader and more inclusive definition of the moral domain may be necessary to incorporate the views of those outside mainstream bioethics.

\section{The study design and conduct ${ }^{7}$}

The analysis presented below is based on qualitative data collected in semi-structured interviews with 15 general practitioners in South Australia during $1993 .^{8-10}$ The general practitioners who took part in interviews were volunteers, recruited through the networks of the Royal Australian College of General Practitioners.

The interviews began with a general question: "Please tell me about an ethical problem you have encountered in your work as a general practitioner", followed by a series of prompts designed to fill out the initial story, their reasons for their actions, why the problem they were describing was an ethical problem, and the influences on the GP's moral decision making.

The GPs came from a wide variety of backgrounds. They ranged in age from 30 to 63 years, with the largest group being aged between 30 and 40 years. Twelve of the 15 were male and 13 were born in Australia. They worked in a mixture of settings: urban and rural; public and private practice; solo through to very large group practice; employed, and partnerships.

The analysis reported in this paper is of the ways in which the GPs described and defined their ethical problems. Each interview was coded for the ethical problems mentioned, for problems the GPs described in detail and for discussion of why the problem was an ethical problem. The analysis used the categories that participants themselves suggested ${ }^{11-13}$ and also drew on explanatory concepts from the literature. ${ }^{14}$ I made some use of simple enumeration techniques. ${ }^{1516}$ The quotations presented below have been chosen because they are representative of the categories from which they are drawn. Where anomalies and disconfirming pieces of evidence arise, these are explicitly mentioned. ${ }^{17-19}$

\section{The problems}

In response to the opening question: "Tell me about an ethical problem you've experienced in 
your work" the GPs identified 44 problems. Six described only one problem or issue, four listed two or three problems and five provided a list of five or six problems from which they selected one or two to discuss.

The GPs discussed stories and issues at three different levels of generality. First, some GPs opened with an issue, which they discussed in general terms. For example Dr Bright (pseudonyms are used throughout this paper) began: "I suppose the main ethical problems a lot of doctors face are those, let us say, before birth". Second, some GPs began with an issue, and, when asked, moved on to discuss this with anecdotes. For example, Dr Silverman began (numbers at the beginning of quotations and in parentheses after a quotation refer to paragraph numbers in the text of the interviews):

2. I suppose the most obvious problem would be contact tracing with STDs.

3. Can you think of an example of that that you can tell me about? (Italics in quotations from the text refer to my questions and comments.)

4. I've got a young lady in hospital that I've just discharged this morning. She is 19 years old and she presented with severe vaginal pain, was seen over the weekend by a couple of doctors at the hospital, none of whom were too sure what was going on, was given various creams which didn't make any difference. Came in here on Monday and had quite obvious genital herpes, cultures of which have subsequently shown positive herpes simplex type one.

Dr Silverman

Male, 32, married, partner in five-person rural practice

The third group of GPs began their interviews with specific stories and narratives, without identifying these stories as being of any particular type. For example, Dr Kingsford began his interview with an account of a recent case:

2. Yes, I guess ethical problems crop up to a minor degree on a lot of occasions. Well, I suppose one recent example was a girl that came to see me, about a 19-year-old girl who had been assaulted by her father. She said a very hard slap on the face, necessitating me putting her into hospital ... She improved-she was quite upset, naturally - and came along with her boyfriend, saying that her father assaulted her and that she was laying charges against him. She had had this argument with him, and he'd lost his temper, struck her, and she was moving out of the home and staying with her boyfriend's mother. Now, this was all quite satisfactory, and she reported it to the local policeman, who later then came down to see me, and I gave them a statement about this and she was still about to obtain a restraining order against the father so that he couldn't approach her. From the other point of view I then saw the father who came to see me a few days later. He'd just been married, he'd been married for the second time, and had a baby at the Women's Hospital who'd had a lot of-who was premature, the mother, his wife, had to be induced because of very severe pre-eclamptic toxaemia, and the baby had some problems due to prematurity with breathing and it was needing to be on oxygen and had needed a lot of support in the months before this and caused quite a bit of tension in the family. He's a person that I've known for quite some time and he denied the whole state of affairs. He denied that he'd struck her, so this was the dilemma-it was her word against him. And the doctor, who was myself, of course in this case, was knowing both people concerned in the dilemma too-who to believe, really, and how it happened.

Dr Kingsford

Male, 57, married, partner in three-person rural practice

Of the 44 problems mentioned in their interviews, the GPs then discussed 23 in some detail (see table 1). Broadly speaking, the problems the GPs in this study identified reflect the published literature on ethical problems in general practice. ${ }^{20-22}$ As such, they share two of the characteristics of those problems: first, measured against the "neon" issues of bioethics they appear mundane and commonplace; second, rather than a focus on moral crises which occur but rarely in general practice there is an emphasis on issues that arise frequently.

\section{The problems as ethical problems}

The more important question addressed in this paper is why the GPs thought these problems mattered or, in other words, why these problems were ethical problems for them. In the bioethics literature, the term "bioethics" is often defined in a fairly broad way. Kuhse and Singer, for example, take bioethics to be a discipline concerned with the ethical dimensions of health care and the biomedical sciences. ${ }^{23}$ Ethical dilemmas, however, are defined rather more narrowly, as situations in which, on moral grounds, persons ought both to do and not to do something. Such a definition implies that issues of conflict and choice are central to moral dilemmas. Most bioethics texts suggest that

Table 1 Ethical problems discussed by the GPs

Relationships with colleagues

Paternalism

Abortion

Confidentiality

Treating family and friends

Chronic drug abuse

Patients changing doctors

Euthanasia

Making mistakes

Domestic violence

Concealing information for a patient

Sickness certificates

Worker's compensation 
100 What makes a problem an ethical problem? An empirical perspective on the nature of ethical problems in general practice

moral dilemmas or ethical problems invariably involve conflict, choosing between equally desirable or undesirable alternatives, or balancing options. For example, Beauchamp and Childress suggest:

"Moral dilemmas occur in at least two forms. (1) Some evidence indicates that act $\mathrm{x}$ is morally right, and some evidence indicates that act $\mathrm{x}$ is morally wrong, but the evidence on both sides is inconclusive. ... (2) An agent believes that, on moral grounds, he or she both ought and ought not to perform act $\mathrm{x} \ldots$ the reasons behind alternatives $\mathrm{x}$ and $y$ are good and weighty, and neither set of reasons is dominant." ${ }^{24}$

In the general practice ethics literature, also, the same definition prevails. The first chapter of Campbell and Higgs's introductory text on "everyday moral choices" is called simply "Choices". Christie and Hoffmaster similarly agree that "moral problems are conflicts of values" ${ }^{26}$

I asked the GPs to explain why the problem or problems they were discussing were ethical problems for them. In all, the GPs offered 24 explanations for why their problems were ethical problems and their explanations can be classified into three categories (table 2). ${ }^{27}$

First, two GPs offered explanations that mirrored the definition of ethical problems in bioethics texts. Dr Elwin's definition was one of these:

65. Why would you say that these ... problems ... are ethical problems?

66. It's a question of definition of ethics, isn't it? Because they relate to your conduct and your professionalism as a general practitioner. That it's a situation where there are several different courses of action, all of which can result in particular outcomes and none of the outcomes is particularly optimal for some reason or other, and you're choosing between several different courses of action none of which you like $100 \%$ and you've got to try and balance in your mind which course of action is appropriate and that often bears back to your own sort of upbringing. What you see as being valuable and what you see as being important in life as much as in, as much as in your sort of professional management. It often relates to your own morals and your own values and what you see as being important as to which course of action you choose and that's why I see it as being ethical because it relates back to your own morals and your own ideas of what is right

Table 2 Why is this an ethical problem? Responses by GPs *

\begin{tabular}{ll}
\hline Type of response & Number of responses \\
\hline Choice and/or conflict & \\
General/formal definition & 2 \\
$\quad$ Personal response & 13 \\
Self-explanatory/public profile & 4 \\
Personal response involving threats to GP's & 5 \\
$\quad$ reputation/integrity & 24 \\
Total & \\
\hline
\end{tabular}

^Excludes two GPs who did not answer this question. and what is wrong and what is the greater thing that needs to be preserved at the expense of the lesser thing - that value's more expendable.

Dr Elwin

Male, 32, married, locum general practitioner in urban areas

Even though only two of the GPs gave definitions that generalised the elements of choice and conflict, there were also thirteen definitions that introduced the notions of choice and conflict in the context of a particular problem. These GPs approached the question personally and answered it in terms of why it had been a problem for them. In eight cases they talked about choices related to whose beliefs, values or interests should take priority. For example, Dr Elwin, in addition to offering a general definition of the nature of ethical problems, also explained why the problem he discussed was an ethical problem for him, by using the idea of a conflict between expectations:

19. The difference is between my expectations of what constitutes good treatment and another doctor's - either another general practitioner's expectations or another specialist's expectations of what constitutes good treatment. And, tying in with that, the issue of who's actually responsible for the patient's care...

Dr Elwin

Male, 32, married, locum general practitioner in urban areas

For three other GPs, their interpretation of an ethical problem was expressed in terms of conflict between alternative possible actions. These GPs thought their problems were ethical dilemmas because they involved choosing the best option from an array of possible solutions. Dr Kingsford explained the nature of ethical problems in this way:

21. Why would you describe it as an ethical problem? What makes it an ethical problem for you?

22. Because, knowing the family for a long time, and there's a sudden split in the family, it's a matter of, it's an ethical problem - do you take this particular line, do you take a side. The ethical problem comes where you've got to make a statement to the police, knowing that the father would be disagreeing with what you're saying. And there's a possibility of losing his confidence and his wife's confidence, who had needed a lot of support with the baby that she'd had that was ill. So there's the dilemma, you see, and that's the ethical problem, as I see it.

Dr Kingsford

Male, 57, married, partner in three-person rural practice

The concepts of choice and conflict are clearly important in the interpretations of "ethical problem" described above. However, if we restrict our 
definition of "ethical dilemma" only to ideas of conflict and choice, some of the nuances of the GPs' understanding of the nature of their ethical dilemmas is lost. For example, Dr Kingsford's interpretation above of the nature of his ethical dilemma also emphasises his relationship with his patients. He was trying to care for all members of this family; even in the face of "a sudden split", he wanted to maintain good relationships with them all.

The GPs offered two other definitions of "ethical problems" that appear to stand outside of definitions focused on choice and conflict. A second group of explanations focused on the publicity that surrounded the issues the GPs had chosen to discuss. Four of the GPs took this approach to emphasise that ethical problems were ethical because they were publicly contentious. For example, Dr Masters explained:

43. We've talked about that one particular ethical problem. Before I ask you some concluding questions, what would you describe as an ethical problem, reflecting on what you've talked about? What makes abortion an ethical problem for you?

44. I'm not really sure. I guess it was just, you know, sort of just under sort of, as an issue that comes up sort of in the media and that comes up across the board at times and I guess most of the doctors would have to at one stage or other come to a decision because it tends to be controversial and it does tend to get flack at times. I think people, you know, most doctors have had to at some time or other in their career come to terms with what they consider to be right, you know, regarding abortion. And, yes, so I guess that's why I count it as ethical.

Dr Masters

Female, 42, married, employed in suburban government-funded community health centre

Dr Masters's response suggests that these problems are ethical ones because they generate public discussion and controversy, and doctors need to form a view on such publicly contentious issues. Her response reflects a view of bioethics, presented particularly in the media, which emphasises life-and-death decision making and in extremi situations. A number of writers in general practice ethics have complained that the agenda in bioethics has been driven for too long by these "neon" issues-problems associated with high technology, beginning and end-of-life questions and, more recently, resource allocation. ${ }^{20}{ }^{21}$ They have argued that the ethical significance of the mundane and subtle problems that arise in general practice has been ignored.

The "neon issues" definition of ethical problems raises questions about the extent to which ethical problems in general practice really are distinctive. There are at least four characteristics of general practice which might suggest that ethical problems in general practice are, at least sometimes, different from those in other health care settings. First, longstanding relationships are much more common in general practice, and these relationships can be important to the resolution of moral problems. Second, families may participate in events in their own right, both as patients themselves, and as concerned relatives with whom the general practitioner deals on a regular basis. In hospital settings, families are more likely to be classified primarily as surrogates of the patient. Third, in general practice, there may be time to "wait and see" how things develop, whereas hospital medicine rarely allows this luxury. Finally, general practitioners often incorporate into their work strategies to prevent ill health in patients, they are not just concerned with the cure of illness or the amelioration of suffering. All of these differences suggest that aligning ethical problems with the "neon issues" of bioethics may not capture some of the more subtle ethical components of general practice. This is not to suggest that the concerns of GPs such as Dr Masters are any less significant, only that they may have been primed to identify problems as ethical ones by their public profile.

A third group of definitions of an ethical dilemma dealt with the notion of threats to the GPs' integrity or reputation. For these GPs, their problems were problems principally because either they were hurt by what was happening to them, or there was a significant chance that they might be hurt. Dr Johnson, who talked about whether to reveal his mistakes to his patients, offered the following explanation:

16. Oh, just the fact, one, you made a mistake. ... But, it was, yeah just that sort of feeling, you know, you've sort of gone, you know that concern that there may be repercussions, which is just what most of us doctors dread, having a letter in the mail. It does happen, you know, but not with something like that. But it has happened-I've heard of cases over just that sort of thing - damages claim-you know, that was the main thing.

Dr Johnson

Male, 36, married, associate in a three-person suburban practice

Dr Dunt's dilemma-related to his decision to support his patient's wish to give birth at home-was very different, but it also revealed a focus on a threat to his integrity and reputation:

46. The biggest problem for me was to fear for myself. There were very real risks.

47. In what sense?

48. If anything had gone wrong that I could be in any way blamed for. I made very serious risks, I knew it. I would get no support. I knew that too. So, and I thought considerably [about it]. I like my practice. I don't wish to be barred from practising medicine. That risk was there.

Dr Dunt

Male, 52, married, solo rural practice 
102 What makes a problem an ethical problem? An empirical perspective on the nature of ethical problems in general practice

These views about the nature of ethical dilemmas are important, since they do not seem to fit into mainstream bioethics accounts of the nature of ethical dilemmas. The dominant interpretation of an ethical dilemma does not easily incorporate dilemmas that are focused around concern for oneself. In fact, Beauchamp and Childress suggest that problems of this nature are, at least, of lesser significance and, perhaps, not ethical dilemmas at all. They argue that self interest and a concern for one's reputation, on the part of the physician, may force hard choices, but these are not hard mora choices ${ }^{28}$ For some GPs, though, it was exactly their concern for themselves and their reputation that made the dilemmas a reality.

The moral problem for some of the GPs in this study centred on their own emotional reaction, and issues of choice, options and decisions between alternatives were of secondary importance. For example, Dr Newton said that her dilemma-how to respond when three patients she and her father had treated for many years left her practice ...

50 ... was a problem because they were three people who I knew very well, I thought I did. I felt I looked after them, to the best of my ability, in fact extremely well. And at times I'd put myself out a lot-not just a little bit-but a lot, on individual instances, and that had always been appreciated, or seemed to have been appreciated..

52 ... I felt hurt that my services had been rejected and then the available practice had been rejected, and in the end those of the practice for a long time. And it's very difficult to think objectively in that instance...

\section{Dr Newton}

Female, 44, married, partner in a two-person inner suburban practice

The mainstream bioethics model of an ethical dilemma has relatively little room for emotion and personal pain, such as that experienced by Dr Newton. The literature on "caring" theories of ethics that has grown out of Carol Gilligan's work on responses to moral situations provides another model that seeks to incorporate a greater emphasis on emotions and relationships. ${ }^{29}$ Gilligan's psychological research has its parallels in philosophical ethics. Annette Baier, for example, maintains that modern moral philosophy has been oriented almost exclusively toward universal rules and principles, with their focus on impartial contracts between disinterested individuals. ${ }^{30}$ This catches only part of the moral life. She suggests we need to build into our understanding of morality an "ethics of care" which takes into account love, trust, and relationships.

The GPs' responses to questions about why their problems were ethical problems provide some support for the view that the moral domain is wider and richer than mainstream bioethics definitions of the nature of moral problems have allowed. I am not suggesting that relational- or care-oriented models of ethics provide a better account of the nature of moral problems and morality. To do this would be to deny the evidence I have presented, which indicates that the majority of the GPs' explanations about moral problems did revolve around conflicts between values and choosing between alternatives. However, the GPs used both of these models, implying that, for them, the moral domain could include a number of ways of thinking about moral problems and morality.

\section{Conclusion}

The GPs in this study provided accounts of the nature of their moral problems that included both the mainstream bioethics definition of a moral dilemma and definitions focused on relationships, harm and public profile. Some of these definitions sit uncomfortably within the dominant model of an ethical dilemma, based on the notion of conflict and choice between competing alternatives. For the most part, though, the GPs defined their ethical problems in ways that were consistent with notions of conflict and choice.

The conclusions to be drawn from this study can be tentative only, but they suggest that the explanation mainstream bioethics offers of the nature of ethical dilemmas is a fair approximation of the GPs' views, but does not account for the whole of the picture. We need, at least, to consider that there may be other, different ways to understand the nature and process of moral deliberation and decision making. The findings of this study suggest that mainstream bioethics does contribute in important ways to the delineation of ethical problems, but that other, broader, conceptions need also to find a voice within bioethics.

\section{Acknowledgements}

The author gratefully acknowledges the support and assistance of her doctoral supervisor, Dr Neville Hicks, and of the anonymous reviewers.

Annette foy Braunack-Mayer, PhD, BMedSci(Hons), is Lecturer in the Department of Public Health, University of Adelaide, Australia.

\section{References}

1 Beauchamp T. Principlism and its alleged competitors. Kennedy Institute of Ethics fournal 1995;5:181-98.

2 Childress J. Principles-oriented bioethics-an analysis and assessment from within. In: DuBose E, Hamel R, O'Connell L, eds. A matter of principles? Ferment in US bioethics. Pennsylvania: Trinity Press International, 1994: 72-98.

3 Green R, Gert B, Clouser KD. The method of public morality versus the method of principlism. Fournal of Medicine and Philosophy 1993;18:477-89.

4 Jonsen A, Toulmin S. The abuse of casuistry. A history of moral reasoning. Berkeley: University of California Press, 1988.

5 The phrase "ordinary people" comes from Elliott C. Where ethics comes from and what to do about it. Hastings Center Report 1992;22:28-35. Elliott argues that "the practical difficulty with applying ethical theories is that ordinary people difficuly with applying ethical theories is that ordinary people pay little attention to theories when they make their moral decisions". I use the phrase "ordinary people" to refer to al the

6 Hoffmaster B. Can ethnography save the life of medical ethics? Social Science and Medicine 1992;35:1421-31. 
7 Braunack-Mayer A. General practitioners doing ethics: an empirical perspective on bioethical methods $[\mathrm{PhD}]$. South Australia: University of Adelaide, 1998

8 Miller WL, Crabtree BF. Primary care research: a multimethod typology and qualitative roadmap. Doing qualitative research. Newbury Park: Sage Publications, 1992: 3-28.

9 McCracken G. The long interview. California: Sage Publications, 1988.

10 Denzin NK. The research act. Chicago: Aldine Publishing Co, 1970.

11 Silverman D. Six rules of qualitative research: a post-romantic argument. Symbolic Interaction 1989;12:215-30.

12 Bernard HR. Research methods in cultural anthropology. California: Sage Publications, 1988: 322-4

13 Strauss AL. Oualitative analysis for social scientists. New York: Strauss AL. Qualitative analysis for social scien
Cambridge University Press, $1987: 30,55-81$.

4 See references 11:218 and 12:322-4.

14 See references 11: 218 and 12. 322-4. Dey I. Qualitative data analysis: a user-friendly guide for social sci-
entists. New York: Routledge, 1993: 219-36.

16 Silverman D. Qualitative methodology and sociology. Brookfield Gower, 1985:138-55.

7 See reference 16: $20-2$

18 See reference $15: 220-36$

19 See reference 12: $319-45$
20 Christie RJ, Hoffmaster CB. Ethical issues in family medicine. New York: Oxford University Press, 1986

21 Smith HL, Churchill LR. Professional ethics and primary care medicine: beyond dilemmas and decorum. Durham: Duke University Press, 1986.

22 A doctor's dilemma: assorted articles on ethical issues in general practice. Australian Family Physician 1994;23:1028-92. 23 Kuhse H, Singer P, eds. A companion to bioethics. London: Oxford, 1998.

24 Beauchamp T, Childress J. Principles of biomedical ethics [4th ed]. New York: Oxford University Press, 1994: 11.

25 Campbell AV, Higgs RH. In that case. Medical ethics in everyday practice. London: Darton, Longman and Todd, 1982.

26 See reference 23: xv.

27 The number does not equate to the number of problems the GPs presented, as a number of GPs offered more than one GPs presented, as a number of GPs offered more than one
explanation for why the issue was a problem and two GPs did not explain why these problems were ethical problems for not expl
them.

28 See reference 25:12.

29 Gilligan C. In a different voice: psychological theory and women's development. Cambridge: Harvard University Press, 1984.

30 Baier A. What do women want in a moral theory? Nous 1985; 19:53-63.

\section{News and notes \\ Annual Intensive One-week Course in Medical Ethics}

The next Annual Intensive One-week Course in Medical Ethics will be held at Imperial College, London from September $17-21$.

For further information please contact: Centre for Continuing Education: email: cpd@ic.ac.uk
Centre for Continuing Education, Imperial College, Room 526, Sherfield Building, Exhibition Road, London SW7 2AZ. Telephone: +44 (0)207 594 6882; fax: +44 (0)207594 6883 . 